\title{
A difícil sintonia entre a Responsabilidade Social Empresarial e a globalização da economia capitalista no discurso da comunicação organizacional
}

\section{Marlene Branca Sólio}

Doutora; Universidade de Caxias do Sul brancasolio@gmail.com

\section{Resumo}

Este artigo é uma reflexão acerca da relação entre os conceitos de globalização, capitalismo, Responsabilidade Social Empresarial e comunicação organizacional. À luz de discussão teórica, busca analisar dados levantados em campo por meio de pesquisa qualitativa desenvolvida em dois momentos: primeiro, na análise de um grupo de entrevistas com líderes de Associações de Moradores de Bairro (Amobs) de Caxias do Sul, no estado do Rio Grande do Sul (RS), e, após, na análise do discurso e de conteúdo de peças promocionais de uma de três organizações inseridas no contexto dos entrevistados. A pesquisa objetivou comparar o discurso das organizações com o discurso dos líderes entrevistados (representantes da população de seus respectivos bairros) na tentativa de compreender o tipo de relação que se estabelece entre eles, em que nível ela denota a presença efetiva da Responsabilidade Social Empresarial de parte das organizações e, também, como os cidadãos percebem o comportamento destas organizações. Parece-nos importante uma reflexão nessa linha, na medida em que o discurso das organizações aparece disruptivo relativamente às suas práticas e na medida em que entendemos que as organizações subestimam a força de mudanças paradigmáticas que despontam na sociedade, bem como a capacidade de leituras transversais (pontos de fuga) dos sujeitos sociais.

\section{Palavras-chave}

Globalização. Capitalismo. Responsabilidade Social Empresarial. Comunicação organizacional. 


\section{Introdução}

Pensar em comunicação organizacional exige uma série de relações que apontam para uma interdependência de conceitos. Nos cenários econômico e político, que, na verdade, nunca estiveram separados ${ }^{1}$, é importante olhar, por exemplo, para a evolução tecnológica, assim como evidenciar aspectos subjetivos - quer de grupos, quer de sujeitos -, agentes significativos no desenho das relações e da cultura. Vivemos em um mundo complexo, que nos obriga a dialogar com conceitos como ideologia, capitalismo, neoliberalismo e globalização, responsáveis pelo ajuntamento da economia com a política e a cultura.

Antes de iniciarmos a análise a que nos propusemos, consideramos importante destacar dois aspectos no que diz respeito à produção intelectual contemporânea dessa área. Ao lado do pensamento complexo, percebemos, ainda, certa tendência em olhar para esses mesmos fatos e fenômenos "descolando-os" de seu contexto histórico, o que significa resignificar sua gênese, a partir de uma atitude simplista e funcional que nada tem de ingênua. Comportamentos, culturas, decisões e reflexões aparecem como bolhas anacrônicas sem que se estabeleça uma relação efetiva com seu passado, mesmo que o recente.

O segundo ponto a evidenciar é o potencial da tecnologia como instrumento de ruptura da hegemonia da informação difundida pela mídia mainstream, mesmo que um grande número de canais alternativos ainda faça eco ao discurso gerado pela mesma. Castells (2004) evidencia, em relação ao novo modelo de sociedade, que a era da informação serve "[...] para reafirmar a ideia de que a cooperação e a liberdade de informação podem favorecer mais a inovação do que a concorrência e os direitos de propriedade". (CASTELLS, 2004, p. 25).

Essa tendência de alteração ou, no mínimo, de pressão sobre o cenário pode ser analisada como um vetor de transformação que Ianni (1999a, p. 49) analisou ao se referir à cultura internacional-popular, que homogeneíza "[...] padrões, estilos, linguagens, modas ou ondas que também se produzem, estilizam e pasteurizam". Em sintonia com Althusser (2003), relembra que o capitalismo reforça sua cultura instalando seus princípios na fábrica, no governo, no exército, na igreja, nos bancos, na escola, no cinema, no teatro, na imprensa, assim como na difusão cultural, material e espiritual. São esses os aparelhos ideológicos (AIE) e os aparelhos de repressão do Estado (ARE), prontos a disseminar a cultura

1 "Não concebo outro lugar para a economia que não o de subdisciplina das ciências sociais, ao lado da história, da sociologia, da antropologia, das ciências políticas e de tantas outras”. (PIKETTY, 2013, p. 557). 
capitalista como um eco da ideologia do sistema constituído². Seu papel é, assim, organizar, desenvolver e reproduzir valores doutrinários que apontem a direção do pensamento e do comportamento de sujeitos, grupos e classes sociais.

É importante, também, pontuarmos a paulatina absorção, pelas organizações, de papéis tradicionalmente desempenhados pelo Estado (segurança, saúde, educação). Parecenos enriquecedor resgatar alguns pontos colocados por Althusser (2003) que explicam esse contexto: o autor mostra em sua obra o Estado como máquina de repressão que permite às classes dominantes assegurar a dominação sobre a classe operária, para poder submetê-la ao processo de extorsão da mais-valia.

Isso se evidencia quando as organizações desencadeiam, para seus públicos internos, campanhas sobre educação em relação ao meio ambiente, como se fossem eles os poluidores, pois na medida em que as empresas assumem este papel e se legitimam nele, elas se isentam de possíveis acusações e ficam na posição do "mestre" (LACAN, 1992).

As questões emergentes nessas campanhas acabam revestindo-se de ingênua abordagem, como nas questões da separação do lixo, da racionalização no uso doméstico da água e da energia elétrica, sem sequer integrar à discussão um olhar sobre as condições de vida dos sujeitos e sobre o contexto em que estão inseridos, tais como: de acirrada competição; de mecanização extremada; de conglomerados com alto poder de barganha; de crise estrutural de emprego, que naturalizam-se na sociedade na medida em que não são tensionadas. Assim, o sujeito pode ver-se compelido a entrar no jogo da barganha, empreendendo todos os esforços possíveis para manter seu emprego/empregabilidade, como problematizado por Freitas (2002): “O emprego é um privilégio em troca do silêncio sobre as condições de trabalho e os efeitos desestabilizadores (psíquicos) das novas práticas de gestão". (FREITAS, 2002, p. 62).

Althusser (1974, p. 67) esclarece que o "[...] aparelho (repressivo) do Estado, unificado, pertence inteiramente ao domínio público". Por outro lado, "[...] a maior parte dos Aparelhos Ideológicos do Estado (em sua aparente dispersão) remete ao domínio privado" (ALTHUSSER, 1974, p. 67), a exemplo de igrejas, famílias, algumas escolas, empresas, entre

\footnotetext{
2 Aparelhos de Repressão do Estado. Expressão que “[...] compreende: não somente o aparelho especializado (no sentido estrito) cuja existência e necessidade reconhecemos pelas exigências da prática jurídica, a saber: a política - os tribunais - e as prisões; mas também o exército, que intervém diretamente como força repressiva de apoio em última instância [...] quando a polícia e seus órgãos auxiliares são 'ultrapassados pelos acontecimentos'; e, acima deste conjunto, o Chefe de Estado, o Governo e a Administração". (ALTHUSSER, 1974, p. 62).
} 
outras, as quais permeiam a produção de significação. Isso nos leva a traçar uma relação entre AIE e poder formal/ AIE e poder informal.

Ianni (1999) destaca que:

[...] é evidente que alguns dos traços principais da sociedade global têm sido desenvolvidos pelas empresas, corporações ou conglomerados multinacionais. Um processo que já começava a esboçar-se em fins do século XIX, com a emergência dos monopólios, trustes, cartéis, desenvolvese de modo cada vez mais intenso ao longo do século XX. (IANNI, 1999a, p. 39).

Mesmo diante dessas verdades, não podemos deixar de sinalizar a complexidade da comunicação na sociedade contemporânea, seu caráter multifocal e a possibilidade de instalarem-se nela pontos de fuga. Lacan nos ensina que há sempre um sentido encoberto por trás do discurso aparente, e o ato falho, o lapso, é seu modo de registro na linguagem. (LACAN, 20073, apud SÓLIO, 2010).

\section{Sobre atores e sobre o público}

É fato que a expansão de empresas, corporações e conglomerados, compreendendo monopólios, trustes, cartéis, multinacionais e transnacionais acentua-se desde o século XVI, configurando-se como centrais a partir da segunda metade do século XX. É preciso evidenciar que o poder das corporações divide espaço com o dos mercados financeiros, capazes de controlar, também, o poder político nacional.

Fala-se, portanto, da geoeconomia. Assim, o poder de regulação que está com o capital, fluido e volátil, separa-se da produção4. É preciso frisar, também, que essa lógica econômica leva à dispersão da responsabilidade sobre tomadas de decisão comprometidas com os interesses de uma minoria econômica dominante e despidas de valor social. É cada vez mais difusa a imagem do decisor, assim como é essencial localizá-los, como descreve Ianni (1999b).

Essa soberania se operacionaliza em escala crescente de acordo com a fusão de capitais, com a formação das sociedades anônimas e com o aumento das escalas das operações; este cenário atualiza o aumento da produtividade, elevando a composição

\footnotetext{
${ }^{3}$ LACAN, Jacques. 0 mito individual do neurótico ou poesia e verdade na neurose. Rio de Janeiro: Zahar, 2007.

${ }^{4}$ Piketty (2013, p. 254) destaca que "Em particular as ações e as participações societárias compõem a quase totalidade das fortunas mais importantes [na Europa]. [...] Nos patrimônios da faixa entre 2 e 5 milhões de euros, a participação dos imóveis é inferior a um terço; acima dos 5 milhões de euros, ela cai para menos de 20\%; e, acima dos 20 milhões de euros, os imóveis respondem por apenas $10 \%$ do patrimônio, enquanto as ações e as participações societárias constituem a quase totalidade do patrimônio. [...] A verdadeira fortuna é sempre constituída de ativos financeiros e profissionais."
} 
orgânica do capital, porém, com redução da demanda de trabalhadores, ou seja, com o aumento das taxas de desemprego.

Ao longo do século XX, o papel preponderante do Estado foi o de aparato/escudo das economias nacionais frente às forças externas desestabilizadoras. Entretanto, seu papel deveria ser o de garantir ao cidadão emprego e bem-estar social (wellfare state) que, nas últimas décadas do mesmo século, sofreu uma inversão de polaridade, fazendo com que economias nacionais precisassem se adaptar às exigências do capital mundial.

A insensibilidade do sistema econômico de mercado em relação aos seus custos externos sobre o meio ambiente social e natural não enxerga que se trata de uma via de crescimento econômico em crise, com as conhecidas disparidades e marginalizações no plano interno, com os atrasos e involuções econômicas, ou seja, com as condições bárbaras de vida, com as expropriações culturais e catástrofes de fome do Terceiro Mundo, e não menos com os riscos de alcance mundial de uma intensa utilização de natureza. (IANNI, 1999a, p. 31).

O autor destaca que os estados-nações rebaixam tanto os dependentes quanto os dominantes, e segue: "Os processos de concentração e centralização do capital [...] invadem cidades, nações e continentes, formas de trabalho e vida, modos de ser e de pensar, produções culturais e formas de imaginar." (IANNI, 1999a, p. 38).

É importante destacarmos alguns atores e seus papéis no cenário descrito. Compreender a lógica de funcionamento das empresas implica em distinguir alguns conceitos para o quais, a rigor, olhamos com displicência: empresário, capitalista, banqueiro e acionista. Cumpre dizer que o empresário

[...] é quem adota novas combinações produtivas. 'Na verdade o empresário é definido por sua função - a de pôr em prática inovações, podendo acumular outras funções econômicas enquanto indivíduo'. [...] Ele pode ser visto como um líder, um pioneiro e um agente de mudança. (POSSAS, 1987, p. 175).

Assim, ele reúne e lidera cientistas, técnicos e capital. A essa figura, atrelam-se a do capitalista, a do banqueiro e a do acionista.

Todavia, o capitalista não é, necessariamente, o empresário. Ele é o detentor de fundos a serem tomados pelo empresário: reúne depositantes, acionistas, e até mesmo uma terceira figura de maior importância na sociedade capitalista: o banqueiro, pois o interesse primordial do capitalista está em emprestar seu dinheiro, comprar títulos no mercado financeiro e especular na bolsa de valores.

O banqueiro será o intermediário entre o empresário e os proprietários dos meios de produção, ou seja, os capitalistas. Seu papel-chave é o fornecimento de crédito, que é o pilar 
no desenvolvimento econômico. Esse conjunto de atores é um dos pilares do modelo capitalista, e seus interesses vão, em muitos momentos, de encontro a um novo paradigma que emule valores relacionados à sustentabilidade ${ }^{5}$, à Responsabilidade Social Empresarial e a um comportamento ético, responsável e de cidadania organizacional em relação aos sujeitos sociais e à natureza.

Isso traduz uma gestão na perspectiva da ecologia profunda, ${ }^{6}$ que implica mudanças nos valores da cultura organizacional e na troca da dominação unilateral pela parceria/cooperação. Também envolve uma mudança correspondente do pensamento mecanicista para o pensamento sistêmico e, por conseguinte, a um novo estilo de administração conhecido como administração sistêmica.

Ianni (1999a) mostra que o estado-nação perde prerrogativas econômicas, políticas, culturais e sociais, debilitando-se, mesmo que, aos poucos, algumas delas aparecem nas decisões e atividades de empresas multinacionais e organizações multilaterais. 0 que era tradicional e reconhecidamente localizado em países, ou em suas capitais, se desterritorializa.

São determinantes no enfraquecimento de projetos nacionais: a reprodução ampliada do capital, que implica na concentração/centralização; o estabelecimento de relações de produção em escala mundial e os "acordos" de interesses de elites dominantes de países ricos e países pobres instauram uma sociedade global nos aspectos econômicos, políticos, sociais e culturais. Isso traduz, em essência, o enfraquecimento do Estado, assim como a vulnerabilidade dos sujeitos sociais que dele dependem e a potencialização da exploração da força produtiva de um lado e, de outro, o fortalecimento de conglomerados/grupos, o enfraquecimento do sentimento de pertença, o aumento da distância entre ricos e pobres e a brutalização do sistema.

Ianni (1999b, p. 147) também destaca que "Na medida em que se forma, consolida e expande, o capitalismo pode influenciar, criar, tensionar, modificar, recobrir ou mesmo dissolver outras formas de organização das atividades produtivas e da vida sócio-cultural".

Corporações transnacionais, cuja geoeconomia e geopolítica nem sempre coincidem com os estados nacionais, se colocam e se impõem no cenário social. Devido a isso, olhar

\footnotetext{
${ }^{5}$ Alguns aspectos históricos sobre sustentabilidade na sociedade contemporânea estão contemplados em Kunsch (2009).

${ }^{6}$ Proposta do filósofo norueguês Arne Naess, em 1973, como uma resposta à visão dominante sobre o uso dos recursos naturais. A Ecologia Profunda demonstra uma distinção frente ao paradigma dominante. No Brasil, nesta mesma época, o Prof. José Lutzemberger propunha ideias semelhantes e desencadeava o movimento ecológico brasileiro com a criação da Associação Gaúcha de Proteção ao Ambiente Natural (Agapan). Disponível em: < http://www.bioetica.ufrgs.br/ecoprof.htm>. Acesso em: 16 out. 2013.
} 
para organismos como Organização das Nações Unidas, Fundo Monetário Internacional e Organização internacional do Trabalho, por exemplo, esclarece essa questão. Pois, como diz Ianni (1999b, p. 186), eles "[...] situam-se cada vez mais na confluência dos estados nacionais e corporações internacionais". Assim, "Em escala cada vez mais acentuada, em âmbito mundial, a 'grande empresa' parece transformar nações das mais diversas categorias em 'pequena nação'”. (IANNI, 1999b, p. 57).

À internacionalização do capital corresponde a dos processos produtivos e ao aumento da exploração social7: "Essa nova divisão internacional do trabalho concretiza a globalização do capitalismo, em termos geográficos e históricos". (IANNI, 1999b, p. 57).

\section{Um novo cenário se compõe}

Os atores sociais responsáveis pela construção do cenário descrito são obrigados, principalmente a partir da década de 70 do século $\mathrm{XX}$, a olhar para um efeito colateral não anteriormente contabilizado: a destruição do ecossistema e a ascensão de um novo paradigma, que joga luz sobre a exploração e a injustiça social desmedidas. Mesmo segmentos alinhados a grupos detentores do poder econômico e político veem-se obrigados a admitir a exploração, a injustiça criminosa e a violação física e moral do meio ambiente e do homem.

Frente a isso, precisamos evidenciar o papel da comunicação comprometida com os valores da sustentabilidade. Essa nova ideia de sustentabilidade na comunicação precisa abandonar a posição de figurante, que opera nos bastidores, para se engajar na construção de uma nova visão de mundo, precisa, também, demonstrar seu poder/competência no sentido de promover a coesão social em torno de ideais descoladas do paradigma modernista - que prioriza apenas aspectos econômicos, de produtividade, de mercado e de consumo, relegando a segundo plano a essência das relações sociais, que consideram conceitos como ética, respeito, justiça social e equilíbrio.

A comunicação organizacional será efetiva quando seus atores tiverem escuta para o discurso do outro, modificando-o e sendo por ele modificados; quando os agentes do discurso reconhecerem que comunicar é mais do que informar (WOLTON, 2002); quando estes mesmos agentes/atores/sujeitos se reconhecerem em vez de dissimularem a efetiva

\footnotetext{
${ }^{7}$ Dois bilhões de pessoas - um terço da população mundial - são vítimas da pobreza, de doenças, da fome, da falta de água potável, e de saneamento básico em vastas áreas do mundo. Essa tendência estará exacerbada, a manter-se a taxa de crescimento populacional, que saltou de menos de quatro bilhões em 1975 para seis bilhões em 2000, devendo chegar a nove bilhões em 2050 (SAVITZ; WEBER, 2007).
} 
relação de forças que provoca um embate no ato de comunicar e quando, na polissemia de cada discurso (BAKHTIN, 1995), houver a consciência de que todo processo comunicativo tem, na sua gênese, abertura para pontos de fuga, que são sempre transformadores.

A insustentabilidade escancarada nas sociedades contemporâneas capitalistas fomentou, principalmente nos anos 70 do século XX, a organização de movimentos sociais que passam a contestar as mazelas sociais, econômicas, políticas e ecológicas. Assim, organizações, Estado e sociedade civil são mutuamente convocados a buscar o desenvolvimento que contemple aspectos sociais por meio de ações embasadas na sustentabilidade, o que significa contemplar atitudes/decisões/ações de respeito ao meio ambiente. Qualquer perspectiva em longo prazo exige, assim, uma mudança de paradigma, que abandone o lucro pelo lucro, e que diminua o abismo social entre exploradores e explorados, além de o desrespeito ao ambiente natural.

Os descaminhos do tratamento ao meio ambiente passam pela extinção de espécies; pela urbanização descontrolada; pelo desmatamento; pela explosão demográfica; pela poluição das águas; do solo e do ar; pela contaminação dos alimentos; pela construção de barragens e usinas, algumas das quais carregam a ameaça nuclear; pela guerra de poder político e econômico, que leva à exploração de povos; pela corrida armamentista; pela guerra bacteriológica; pela desumanização do indivíduo; pelo consumo desenfreado, que leva à produção de toneladas de lixo, entre outros descalabros. É importante evidenciar que, no quadro descrito, os sujeitos sociais são, ao mesmo tempo, vítimas e algozes.

Já nas duas primeiras décadas do século XX ganha força a ideia ou visão de mundo como sistema. Gonçalves (2010) lembra que as descobertas científicas desse século, principalmente as provenientes da biologia, apontam para um conceito menos ambíguo e vago da natureza e do meio ambiente: o de ecossistema, ideia cuja difusão teve início já com Durkheim e Malinowski, com urbanistas, sociólogos e geógrafos da Escola de Chicago. A evolução desse paradigma leva a metáforas como:

[...] a diversidade ecológica apresenta resistência maior contra agressões e perturbações quando o ecossistema tem uma fronteira aberta para outros ecossistemas e quando o limite entre dois ecossistemas é impreciso, o que faz com que cada um dos ecossistemas vizinhos se constitua tendo como um de seus componentes as sucessivas invasões e migrações de um a outro. Todavia, há que se ressaltar que a diversidade não é "incompatível" com a existência de uma espécie dominante. Aliás, todo ecossistema é dominado por uma ou várias espécies que formam o grosso da biomassa. (GONÇALVES, 2010, p. 72). 
O problema está na exploração desmedida e predadora, que acaba por ameaçar de extinção dominantes e dominados. Isso ocorre, por exemplo, quando a exploração abusiva da mão de obra inibe o desenvolvimento de um mercado consumidor, o que se traduz em ameaça a exploradores e explorados, o que faz lembrar Ana Carolina, em Nada te faltará, quando diz: "Mais de um bilhão de chineses. Marchando sem deuses. E outros descalços fazendo sapatos". (CAROLINA; VOLLEROY, 2006).

\section{Paradoxos do sistema}

A partir do século XVIII, ciência e técnica assumem lugar central na vida do homem e nos processos de relações sociais/organização de grupos, cenário que se intensifica até a segunda metade do século XX, quando tem início à reconfiguração, estimulada por crises endógenas e recursivas do próprio sistema capitalista.

Morin diz que:

Toda ação escapa à vontade de seu autor quando entra no jogo das interretro-ações do meio em que intervém [...]. A ação não corre apenas o risco de fracasso, mas de desvio ou de perversão de seu sentido inicial, e pode até mesmo voltar-se contra seus iniciadores. (MORIN, 2001, p. 89).

Isso leva a pensar no momento em que o homem começa a ver-se como parte daquilo que julgou, por longo tempo, à submissão dos seus desmandos: o ecossistema. Iniciam, aí, as reflexões que ponderam a dicotomia razão/emoção; objetividade/subjetividade; o racionalismo que abre flancos à inter/transdisciplinaridade e que permite um olhar sobre o mundo não mais funcionalista/estruturalista/positivista apenas, mas como algo complexo, fluido, flexível, em que múltiplas possibilidades se interpenetram e se contaminam.

Essa mudança de cenário traz à luz a exploração salarial e a subordinação do valor de uso ao valor de troca das mercadorias, assim como a subordinação do ecológico ao econômico, a exacerbação do consumo, a injustiça social como forma de perpetuação da exploração e a alienação como estratégia de manutenção ideológica de uma minoria dominante/exploradora decorrentes do fato de que "[...] toda forma de produção cria as relações jurídicas e políticas sem as quais ela não pode funcionar". (IANNI, 1979, p. 23). Por isso,

[...] um reservatório de mão-de-obra praticamente inesgotável tornou-se disponível nos países em desenvolvimento nos últimos séculos... Segundo, a divisão e subdivisão do processo produtivo estão agora tão avançadas que a maioria destas operações fragmentadas pode ser realizada com um 
mínimo de qualificação profissional adquirida em pouco tempo. (IANNI, 1999b, p. 18-19).

Isso nos permite resgatar a ideia de que as organizações ocupam um lugar central na sociedade contemporânea (KARKOTLI, 2006; SÓLIO, 2013), o que torna difícil pensar a teoria organizacional destacada do contexto social em que elas atuam e se desenvolvem. Da mesma forma, é difícil ignorar as condições estruturais ao considerar as inovações conceituais, pois o modo como elas se desenham e atuam é interdependente dos fatores políticos, econômicos e sociais em que elas se inserem, atualizando-se entre causa, consequência, meio e fim, em movimentação permanente.

É fundamental, pois, a atenção às questões de sustentabilidade, na tentativa de substituição de um modelo econômico predador, que passa pela Responsabilidade Social Empresarial e, mais do que isso, pelo seu caráter de permanência/efetividade, na medida em que somente se atualiza quando é

[...] sempre em qualquer hora ou momento, em todos os projetos sociais, faz parte do dia-a-dia da pessoa física ou jurídica; já social responsável é "fazer" algo em benefício do social para aquele momento, aquele projeto, ajuda naquela situação, mas não faz parte do dia a dia da pessoa física ou jurídica. (KARKOTLI, 2006, p. 10).

A afirmação está em sintonia com o que dizem Baldissera e Sólio (2005) e Sólio (2012), ao proporem quatro Índices de Cidadania Organizacional (ICOs) que categorizam a atuação social das empresas:

Quadro 1 - Índices de Cidadania Organizacional

\begin{tabular}{|l|l|}
\hline Índice & \multicolumn{1}{|c|}{ Característica } \\
\hline Ico 1 & $\begin{array}{l}\text { Aplicação dos postulados mais elementares para sua constituição/permanência, } \\
\text { resultando no que classificam como Indicador de Cidadania Organizacional 1. }\end{array}$ \\
\hline Ico 2 & $\begin{array}{l}\text { Busca pela minimização de problemas mediante estímulo e pela facilitação de ações que } \\
\text { qualifiquem o entorno, também, as relações que aí se atualizam mediante criação de } \\
\text { espaços, disponibilização de recursos e orientações especializadas, apoio com horas de } \\
\text { trabalho e outras formas de doação/subvenção. Com isso, inicia o comprometimento da } \\
\text { organização com o meio ambiente/sociedade de modo responsável e participativo. }\end{array}$ \\
\hline Ico 3 & $\begin{array}{l}\text { Engajamento em projetos comprovadamente idôneos de desenvolvimento sociocultural, de } \\
\text { redução de diferenças econômicas, de preservação/reparação ambiental, social e cultural e } \\
\text { de desenvolvimento de pessoas/comunidades com caráter de permanência/continuidade } \\
\text { (boas práticas). }\end{array}$ \\
\hline Ico 4 & $\begin{array}{l}\text { Pressuposição de que a possibilidade organizacional seja diretamente interdependente de } \\
\text { sua ação-cidadã, isto é, em nível epistêmico, qualquer pensar, apresentar-se e/ou agir } \\
\text { deverá ser legitimado pela postura ética, moral, responsável e cidadã. }\end{array}$ \\
\hline
\end{tabular}

Fonte: elaborado pela autora com base em Baldissera e Sólio (2005) e Sólio (2012). 
Em resposta à crescente pressão social, configura-se um esforço midiático de organizações empresariais com o intuito de promoverem suas marcas como sustentáveis (SÓLIO, 2013). Todavia, podemos perceber que o discurso sustentável ${ }^{8}$ de certas corporações é simplesmente uma nova roupagem para vender seu produto, o que as caracteriza a partir de ações de marketing social, filantropia e/ou assistencialismo e as define como instituições meramente econômicas, com responsabilidade consubstanciada no lucro máximo a um custo mínimo, sem considerar as variáveis sociais e ambientais mesmo exercendo influência determinante na variável política.

É fato que as empresas convivem com a multiplicação de fontes de notícia, que funcionam 24 horas por dia, o que inclui desde redes de televisão a cabo até blogs e mídias sociais. Além disso, reputação, marca e demais ativos intangíveis se transformaram em importantes vetores de valor: "Quando 75\% dos ativos são intangíveis, como ocorre, em média, com as empresas da Fortune 500, é óbvio que qualquer ataque à reputação da empresa pode acarretar consequências financeiras devastadoras". (SAVITZ; WEBER, 2007, p. 57).

A essência do desenvolvimento passa a associar-se, portanto, ao conceito de sustentabilidade, que implica na interdependência das dinâmicas econômica, social, política e ecológica desenvolvidas por meio de uma educação comprometida e difusora da ética ambiental. Cada vez mais, o crescimento econômico precisa contabilizar aspectos qualitativos, além dos quantitativos; isso significa que distribuir renda entre os proprietários dos fatores/meios de produção pode representar crescimento, mas não, necessariamente, vai refletir desenvolvimento ${ }^{9}$, algo que exige a caminhada da economia

\footnotetext{
8 Teoricamente, é aquele que preserva o meio ambiente, sobretudo os recursos naturais não renováveis, mas que, também, preocupa-se com o bem-estar dos sujeitos sociais (justiça social).

9 O Índice de Desenvolvimento Humano (IDH), medida comparativa que classifica os países de acordo com seu grau de "desenvolvimento humano", categoriza os países em 'desenvolvidos' (desenvolvimento humano muito alto), 'em desenvolvimento' (desenvolvimento humano médio e alto) e 'subdesenvolvidos' (desenvolvimento humano baixo). Já os índices de expectativa de vida ao nascer, educação e PIB (PPC) são os indicadores de padrão de vida para as estatísticas. 0 IDH foi desenvolvido em 1990 pelos economistas Amartya Sen e Mahbub ul Haq e aplicado desde 1993 (PNUD - Programa das Nações Unidas para o Desenvolvimento Humano) em seu relatório anual, o Relatório de Desenvolvimento Humano (RDH); este, avalia o desenvolvimento pelos avanços econômicos e por melhorias no bem-estar humano. A partir do relatório de 2010, o IDH combina três dimensões: educação (anos médios de estudos), longevidade (expectativa de vida da população) e Produto Interno Bruto per capita. O IDH vai de zero (nenhum desenvolvimento humano) a 1 (desenvolvimento humano total). Quanto mais próximo de 1, mais desenvolvido é o país. Em 2011, foram avaliados 187 países. Considerando-se o IDH, os 20 países melhor classificados são: Noruega, Austrália, Países Baixos, Estados Unidos, Nova Zelândia, Canadá, Irlanda, Liechtenstein, Alemanha, Suécia, Suíça, Japão, Hong Kong [sic], Islândia, Coreia do Sul, Dinamarca, Israel, Bélgica, Áustria e França; já os 10 países com IDH mais baixo são Benin, Gâmbia, Sudão, Costa do Marfim, Malawi, Afeganistão, Zimbabue, Etiópia, Mali, Guiné-Bissau, Eritreia, Guiné, República Centro-Africana, Serra Leoa, Burkina Faso, Libéria, Chade, Moçambique, Burundi, Níger e República Democrática do Congo. Disponível em: <www.infoescola.com/geografia/idh-2011> e $<$ www.suapesquisa.com>. Acesso em: 10 jun. 2013.
} 
como um todo na direção do equilíbrio e da justiça distributiva para o conjunto das populações.

Fica evidente, por exemplo, o crescimento da economia frente ao investimento maciço na informatização de processos/robotização de tarefas. A redução de custos e aumento das margens de lucratividade levam, nesse caso, ao aumento dos índices de desemprego e à potencialização da capacidade de barganha do empregador frente ao excesso de mão de obra, o que, na outra ponta, representará redução do poder de compra e retração de um mercado consumidor potencial.

Uma nova visão de mundo contempla, ao contrário, conceitos como gestão ambiental responsável, capitalismo consciente/produção colaborativa, ética empresarial e indicadores de desenvolvimento humano. Além disso, supor que os sujeitos sociais tomam como parâmetro o discurso organizacional - que normalmente parte do pressuposto de que seus públicos precisam "ser educados" para respeitar o meio ambiente - mostrou-se equívoco, de acordo com entrevistas desenvolvidas ao longo da pesquisa que gerou este trabalho. Afirmações como: "A gente percebe que a maneira com que as empresas tão atuando nas sociedades, elas tão destruindo, né. A gente tá dando um prazo de validade muito curto pra essa existência, por causa da maneira que as empresas tão atuando".

\section{0 que é dito e o que se ouve}

Se quisermos refletir acerca das falas colhidas em 3710 entrevistas feitas em profundidade, operadas com líderes de Associações de Moradores de Bairro (Amobs), precisamos destacar alguns conceitos como poder/relações de poder e ideologia, com o qual nos pautamos em Foucault, Althusser e Pêcheux. Feita essa reflexão, recorremos também a Bardin (2000), com o objetivo de categorizar algumas falas recorrentes encontradas nas entrevistas, que se opõem ao discurso adotado pelas empresas analisadas em suas peças promocionais/institucionais.

\footnotetext{
10 Foram aplicadas 37 entrevistas em profundidade, de um total de 212 Associações de Moradores de Bairro ativas. Selecionamos três dentre as empresas mencionadas nas entrevistas, analisando o discurso por elas adotado (Twitter, Facebook, cartazes, folhetos e jornais/revistas organizacionais digitais). Neste artigo, usamos como exemplo o discurso de uma das empresas selecionadas, embora devamos registrar que as demais organizações levaram a resultados de análise muito semelhantes. As entrevistas em profundidade desenvolveram-se em salões comunitários de diferentes bairros da cidade e no campus da Universidade de Caxias do Sul. Portanto, as entrevistas desenvolvidas no campus da UCS foram todas individuais e as desenvolvidas em salões comunitários reuniram pequenos grupos de líderes, o que se mostrou efetivamente mais proveitoso, na medida em que o diálogo provocava discussão de pontos de vista e comparação de situações vivenciadas pelos líderes reunidos e pelas comunidades que eles representavam. A partir da gravação das entrevistas, desenvolveu-se a técnica metodológica da Análise de Discurso, que pautou também a análise das peças de comunicação das três empresas selecionadas. Antes de desenvolvermos a $\mathrm{AD}$ das peças de comunicação, a técnica metodológica adotada foi a Análise de Conteúdo, pautada em Bardin (2000).
} 
Pensar os processos comunicacionais é pensar o discurso, pois é por meio da linguagem que o sujeito acontece. A articulação da linguagem leva à criação do sentido, alem de que é na cadeia significante que está à possibilidade de geração de múltiplos desses sentidos, pois "[...] todo Sujeito que engaja seu Discurso no curto-circuito da falação faz necessariamente ouvir muito mais do que ele crê dizer". (DOR, 1993, p. 154).

Quando, por exemplo, uma organização, em uma de suas mídias sociais, afirma que teve sua capacidade operacional e de oferta de serviços reduzida em função da Lei 12.619, de 30 de abril de 2012 (BRASIL, 2012), que regulamenta a profissão de motoristas, está dizendo muito mais do que aquilo que publicou nas redes sociais. Ou, quando usa dados precisos, com linguagem denotativa, ao mostrar sua imagem ao mercado: incorporação de 20 caminhões à frota; investimento de R \$1,5 milhão em nova filial; aquisição de área com 30 mil m². Porém, ao falar em Responsabilidade Social Empresarial, a empresa aparece como "figurante" em duas campanhas nas quais se configura como voluntária, sem ostentar números ou fatos concretos. Também menciona conscientização em treinamento de motoristas, o que na verdade é de seu interesse e sua obrigação como empregadora; e conscientização da comunidade, quando, na verdade, não explica como operacionaliza nem divulga qualquer matéria sobre o assunto em suas mídias sociais ou na imprensa. Importa observar nos exemplos colocados o uso constante dos conceitos treinamento e conscientização, o que a coloca, como já referimos, na posição do "mestre".

Em outro momento, a empresa menciona sua gestão ambiental, que inclui o uso de veículos menos poluentes; a destinação correta de descarte de pneus, óleos, lubrificantes, lâmpadas e baterias e a realização de testes de opacidade da fumaça em toda a frota e lavagem com água da chuva. Não esclarece, entretanto, o que define como "menos poluente", também, não parece mostrar dados concretos nem comparativos sobre o assunto. Além do mais, as medidas mencionadas traduzem no mínimo que se esperaria de uma empresa cumpridora da lei e da ética.

Uma série de frases de efeito, com apelo emotivo, compõe o discurso da organização, desacompanhadas de dados concretos, mas divulgadas em mensagens com esmero visual estético e imagens sedutoras. Lemos, por exemplo: "Cuidar com atenção especial das pessoas que representam a empresa" e "Presta homenagens à equipe valorizando a particularidade de cada momento"; assim como vemos uma nota em solidariedade às vítimas do incêndio na Boate Kiss (Santa Maria, 2013), comportamento que se repete em relação ao Dia Mundial do Meio Ambiente e ao Dia da Natureza (a [nome da empresa] "tem o 
maior orgulho em contribuir com a preservação da natureza, através de práticas simples, mas eficientes").

Ao mesmo tempo, ouve-se de lideranças comunitárias, referindo-se a uma organização do bairro: "Só com notificação. Pra comunidade, a empresa não respondeu, mas quando veio a fiscalização ela não tem o que fazê".

Foucault (1979, p. 6) mostra o discurso como “[...] um jogo estratégico e polêmico de ação e reação, pergunta e resposta dominação e esquiva, luta. [...] Espaço em que saber e poder se articulam". Diz, ainda, que quem fala o fazer de um lugar reconhecido institucionalmente (autoridade do discurso), portanto, faz circular o saber (institucional) e, com isso, gera poder (da Igreja, por exemplo, ou o da ciência). A produção desse discurso gerador de poder é organizada e distribuída por procedimentos cuja função é eliminar todo tipo de ameaça a sua permanência.

Esse jogo fica muito claro quando os líderes comunitários relatam respostas obtidas frente às poucas demandas feitas: a responsabilidade, no que diz respeito à segurança, é do poder público, pois elas [as empresas] já pagam impostos. Ou, quando as organizações repassam ao trabalhador instruções sobre como separar resíduos, fazendo valer a autoridade (institucional) de seu discurso como se o problema da poluição estivesse em relação direta com o cuidado do lixo doméstico dos empregados. O que se vê aí é, justamente, a circulação de um saber que gera poder, campanhas internas ingênuas como doação de mudas, ou circulação de flyers com instruções simplistas sobre descarte e embalagem são os exemplos mais clássicos do que descrevemos.

Assim, a "ordem discursiva" (REVEL, 2002), própria de um período particular, possui uma função normativa e reguladora e coloca em funcionamento mecanismos de organização do real por meio da produção de saberes, de estratégias e de práticas; daí a possibilidade de uma palavra assumir sentidos opostos, dependendo do discurso em que esteja inserida. 0 dito popular, lembrado por um dos entrevistados, traduz bem esse contesto: segundo ele, "pintar o diabo de azul não o faz menos perigoso, mas o deixa menos assustador".

Bakhtin (1995, p. 32) mostra a palavra como "a arena privilegiada onde se desenvolve a luta de classes". Ou seja, pode-se dizer que "[...] os diversos discursos materializam-se em 'visões de mundo' das diferentes classes sociais com seus interesses antagônicos: são as várias formações ideológicas correspondentes às várias formações discursivas". (BRANDÃO, 2000, p. 52). 
Já para Pêcheux (1988, p. 160), “[...] as palavras, expressões, proposições, etc. mudam de sentido segundo as posições sustentadas por aqueles que as empregam, o que quer dizer que elas adquirem seu sentido em referência a essas posições, isto é, em referência às formações ideológicas nas quais essas posições se inscrevem". Um exemplo clássico do que está posto é o fato de as organizações convencerem seus empregados de que seu papel prioritário é gerar lucro, sem o qual certamente desaparecerão, deixando de oferecer emprego, que esse mesmo discurso aponta como motor para o desenvolvimento social.

Foucault nos mostra que há uma formação discursiva

No caso em que se puder descrever, entre um certo número de enunciados, semelhante sistema de dispersão, e no caso em que entre os objetos, os tipos de enunciação, os conceitos, as escolhas temáticas, se puder definir uma regularidade (uma ordem, correlações, posições e funcionamentos, transformações) [...]. (FOUCAULT, 1987, p. 43).

O que o autor denomina de formação discursiva, portanto, é um conjunto de performances verbais, ligadas no nível dos enunciados. 0 que legitima uma frase, na verdade, uma proposição ou um ato de fala como enunciado é a função enunciativa, ou seja, ele ser produzido por um sujeito a partir de um lugar institucional, determinado por regras sócio-históricas que o permitem que seja enunciado. Não há enunciado [...] livre, neutro e independente; mas sempre um enunciado fazendo parte de uma série ou de um conjunto, desempenhando um papel no meio dos outros, neles se apoiando e deles se distinguindo [...]". (FOUCAULT, 1987, p. 114).

A cartilha do modelo de economia neoliberal exemplifica essa citação se recapitularmos o papel de mero coadjuvante a que relega o Estado, mesmo que as organizações estejam cientes de que "Apesar de todos os protestos em contrário, combinados com fantasias neoliberais relativas ao recuo das fronteiras do Estado, o sistema do capital não sobreviveria uma única semana sem o forte apoio que recebe do Estado". (MÉSZÁROS, 2003, p. 93).

Mas precisamos observar que a recepção não é apática, fazendo uma leitura unívoca do discurso. No mundo do trabalho, uma série de mediações permeia as relações entre organização e recepção, gera tensões, conflitos, identificações e aderências. É importante, também, contemplarmos os aspectos da subjetividade dos sujeitos, ao lado das "colagens" que trazem para a instituição em que atuam ou com as quais se relacionam, seja como 
cidadãos ou como consumidores, considerando que a manipulação de elementos simbólicos corresponderá ao jogo-resposta.

Silenciar não significa compactuar. Isso se confirma quando ouvimos, no campo: "Algumas pessoas estão passando mal. Ainda têm esgoto a céu aberto. [...] e o cheiro é terrível." Ou: "Como denunciar? Perder o emprego? As empresas não têm a menor dúvida em demitir".

O discurso emitido pelas organizações não será, necessariamente, aquele ouvido por seus interlocutores. A subjetividade dos sujeitos, suas experiências, vivências e relações colarão ou desnudarão nele o não dito, o não explicitado, que de alguma forma está ali, por trás do texto. Subestimar a capacidade de os sujeitos sociais apreenderem as sombras do texto é ingênuo, assim como é ingênuo supor que a atualização desta compreensão se daria pela gramática do autor desse discurso (a organização).

A totalidade dos entrevistados, por exemplo, afirma a ausência de diálogo entre as comunidades e as empresas nelas inseridas em oposição ao discurso organizacional padrão. Os entrevistados sinalizam a falta de consciência social das organizações, ao mesmo tempo em que garantem: "O pessoal sabe dos seus direito." Ao avaliar a postura organizacional em relação à RSE, as notas atribuídas pelo grupo variaram entre 3, 4 e 5, o que mostra uma leitura pluralizada.

\section{Amarras de ideologia e poder}

A aceleração dos processos industriais, no final do século XIX, destaca um conceito que Foucault (1987) aborda: o controle, essencial na formação da sociedade capitalista, em que é imperioso, segundo ele, controlar fluxos e distribuição espacial da mão de obra, satisfazendo as necessidades da produção e do mercado de trabalho. Ao olharmos para a distribuição geográfica de alguns dos maiores conglomerados internacionais - concentrados em países asiáticos, nos quais a mão de obra é abundante e barata -, vemos a atualidade da reflexão do pensador. 0 controle social funciona de modo capilar, passando pela justiça, por instituições de saúde, criminológicas, pedagógicas e atreladas a mecanismos de assistência, a associações filantrópicas e patrocinadores.

0 poder se atualiza, assim, em pequenos enfrentamentos cotidianos, disputas e microlutas, medidas de força que envolvem sujeitos e instituições em tensão permanente. (FOUCAULT, 1987). Supor que os sujeitos sociais não se dão conta das articulações entre poder/saber/ideologia é uma posição ingênua, principalmente quando se ouve afirmações 
como: "A causa maior dessa desmobilização é a falta de interesse político"; "Eles [moradores] viriam junto conosco [Presidente de Amob]. Eles nos apoiariam. Eles engajariam mais, mas não adianta você ir lá pedir, que eles não vão te dar [Poder Público e empresários]”. "Mas quando eles, é, e quando eles ganham isenção disso, isenção daquilo aí eles não falam nada [empresas]." "E aí o pior, que é a segunda perversidade, né, aonde acontece qualquer um fato negativo no bairro é porque é tudo marginal."

Deter poder implica, evidentemente, controlar o campo do saber. Assim, a disputa se dá, também, pela produção de significação, o que nos leva a pensar nos processos de organização desse saber e em sua corporificação/atualização como cultura, carregada, evidentemente, de aspectos ideológicos. Isso nos faz derivar para questões relacionadas ao poder simbólico, à identidade e à construção de imagem - conceitos que se atualizam em práticas centradas na arquitetura/manutenção de uma sociedade cujo princípio fundamentador é a economia capitalista.

As organizações não existem senão inseridas em contextos sociais, mesmo que se esteja falando de espaços virtuais. Sob aspectos múltiplos, elas estão, inevitavelmente, relacionadas. Pensar a cultura organizacional, portanto, leva a pensar nas ciências sociais e na geração de formas simbólicas, o que nos conduz a uma concepção multidisciplinar e dinâmica. A partir disso, é possibilitado a reflexão sobre o conceito de cultura pelo viés semiótico adotado por Geertz (1989). O autor vê o homem como um animal amarrado a teias de significados que ele mesmo teceu:

Assumo a cultura como sendo essas teias e a sua análise; portanto, não como uma ciência experimental em busca de leis, mas como uma ciência interpretativa, à procura do significado. É justamente uma explicação que eu procuro, ao construir expressões sociais enigmáticas na sua superfície. Todavia, essa afirmativa, uma doutrina numa cláusula, requer por si mesma uma explicação. (GEERTZ, 1989, p. 4).

Assim, podemos pensar a cultura organizacional como um emaranhado de significados, significações, interpretações e transformações de contextos com relações entre si. Autoridade, poder, disciplina, hierarquia, participação, comprometimento, autonomia e dependência são valores e conceitos diferentemente interpretados, analisados e dimensionados em contextos em relação, o que provoca análise, reflexão, interpretação e simbolização ${ }^{11}$ em diferentes níveis, em uma permanente dinâmica de contaminação. A isso é que denominamos cultura. É Bourdieu (2010) quem alerta:

\footnotetext{
11 “O poder simbólico é, com efeito, esse poder invisível, o qual só pode ser exercido com a cumplicidade daqueles que não querem saber que lhe estão sujeitos ou mesmo que o exercem". (BOURDIEU, 2010, p. 8).
} 
As diferentes classes e fracções de classes estão envolvidas numa luta propriamente simbólica para imporem a definição do mundo social mais conforme aos seus interesses, e imporem o campo das tomadas de posições sociais [as tomadas de posição ideológica dos dominantes são estratégias de reprodução que tendem a reforçar dentro da classe e fora da classe a crença na legitimidade da dominação da classe]. (BOURDIEU, 2010, p. 11).

Posto dessa forma, o conceito se opõe ao defendido nas organizações, que olham para sua cultura como algo cristalizado, asséptico, sem considerar os microcosmos representados por sujeitos em relação e sem considerar as transformações que esses sujeitos imprimem no cenário organizacional.

A cultura pode expressar diferentes formas de vida e/ou visões de mundo, relacionando-se a problemas/situações/contextos sociais e políticos. Dessa forma, podemos dizer que cada sociedade tem seus valores e sua ética, e que estes se constituem em sua cultura: "aquele todo complexo que inclui conhecimento, crença, arte, moral, lei, costume e quaisquer outras capacidades e hábitos adquiridos pelo homem na condição de membro da sociedade". (TYLOR, 2005, p. 69). Cultura, assim, imbrica-se na trajetória histórica e na de classes.

Por essa ótica, os valores culturais se alteram em cada período histórico e de acordo com a classe no poder, por isso, não há como conceber um conceito de cultura organizacional despegado da luta de classes, da disputa de poder e da ideologia prevalente no cenário social.

\section{Considerações finais}

$\mathrm{Na}$ medida em que o comportamento organizacional tende ao encapsulamento e os pontos de fuga e fendas nas articulações de poder se atualizam, dando espaço a mudanças endógenas de cenário, as organizações serão obrigadas a admitir que há outros players na construção do social e que esses players têm competência para imprimir um processo de basculamento do poder, exigindo delas [empresas] uma nova postura.

A análise do discurso dos entrevistados e a análise do discurso das organizações estudadas apontam para a direção de que os atores sociais têm consciência da necessidade de mudança de cenário; além de reconhecerem a falta de vontade política dessa mudança e perceberem os mecanismos que os mantêm à margem do poder; também reconhecem, no discurso das organizações, o jogo-resposta às pressões que elas sofrem. 
Cabe, ainda, o alerta para a necessidade de um redirecionamento efetivo frente ao fato de: o arrefecimento da concorrência não passar pela globalização econômica; o capitalismo, depois de sucessivas crises endógenas, não ter encontrado uma fórmula para a privatização da produção (centrada na exploração do trabalho); um cenário cada vez mais centrado em tecnologias abrir flanco para a capilarização de informações e, em última análise, do saber, que - relembrando Foucault (1979) - estar intimamente ligado ao poder; um mercado com capacidade para o consumo ser necessário ao desenvolvimento do capitalismo.

Percebemos que a relação de exploração de mão de obra, a apropriação da mais-valia e a necessidade de dominação são ingredientes essenciais à estrutura ou atualização do modelo capitalista de sociedade. Essa combinação pressupõe uma hierarquia nas relações de poder, que ao mesmo tempo autoriza o "monopólio" do saber e determina suas formas de distribuição.

A legitimação desse quadro passa, então, segundo entendemos, pelo discurso da organização, que busca materializar o fantasma de que é a provedora dos atores sociais já que, ao se apropriar do discurso (enquanto linguagem), ela está "autorizada" no campo simbólico, em que se "legitima" no papel de responsável pela sobrevivência do sujeito, mesmo que, na realidade, como escreve Mészaróv (2003) "do perverso ponto de vista do 'processo de realização' do capital, consumo e destruição são [sejam] equivalentes funcionais". (MÉSZARÓV, 2003, p. 22, grifos do autor).

Neste trabalho, porém, percebemos, ao cotejar o discurso organizacional e o discurso social, que as organizações não levam em conta o imaginário do ator social, o que conduz ao que aqui chamamos de pontos de fuga, principalmente porque o cenário das vivências/experiências/impressões deste ator o torna opaco àquele discurso, na medida em que não encontra nele qualquer correspondência significante.

\section{Referências}

ALTHUSSER, Louis. Aparelhos ideológicos de Estado. São Paulo: Graal, 2003.

ALTHUSSER, Louis. Ideologia e aparelhos ideológicos de Estado. Lisboa: Presença, 1974.

BAKHTIN, Mikhail. Marxismo e filosofia da linguagem: problemas fundamentais do método sociológico na ciência da linguagem. 9. ed. São Paulo: Hucitec, 1995. 
BALDISSERA, Rudimar; SÓLIO, Marlene Branca. Responsabilidade, ética e comunicação: reflexões sobre a tensão organização ecossistêmica. In: PANERAI, Margarete Araújo; BAUER, Maristela Mercedes (Org.). Desenvolvimento regional e responsabilidade social: construindo e consolidando valores. Novo Hamburgo: Feevale, 2005. p. 23-36.

BARDIN, Laurence. Análise de conteúdo. Tradução de Luís Antero Reto e Augusto Pinheiro. Lisboa: Edições 70, 2000.

BOURDIEU, Pierre. 0 poder simbólico. Rio de Janeiro: Bertrand Brasil, 2010.

BRANDÃO, Maria Helena. Introdução à análise do discurso. 7. ed. Campinas: Unicamp, 2000.

BRASIL. Lei 12.619, de 30 de abril de 2012. Diário Oficial [da] República Federativa do Brasil, Brasília, 2 maio 2012.

CAROLINA, Ana; VOLLEROY, Antonio. Nada te faltará. Intérprete: Ana Carolina. In: CAROLINA, Ana. Dois quartos. [S.l.]: Sony BMG Brasil, 2006. 1 CD.

CASTELLS, Manuel. A galáxia da internet: reflexões sobre internet, negócios e sociedade. Lisboa: Fundação Calouste Gulbenkian, 2004.

DOR, Joel. 0 pai e sua função em psicanálise. Rio de Janeiro: Zahar, 1993.

FOUCAULT, Michel. Arqueologia do saber. Rio de Janeiro: Forense Universitária, 1987.

FOUCAULT, Michel. Microfísica do poder. 17. ed. Rio de Janeiro: Graal, 1979.

FREITAS, Maria Ester de. Cultura organizacional: identidade, sedução e carisma. 3. ed. Rio de Janeiro: FGV, 2002.

GEERTZ, Clifford. As interpretações das culturas. Rio de Janeiro: LTC, 1989.

GONÇALVES, Carlos Walter Porto. Os (des)caminhos do meio ambiente. São Paulo: Contexto, 2010.

IANNI, Octávio. A sociedade global. Rio de Janeiro: Civilização Brasileira, 1999a.

IANNI, Octávio. Imperialismo e cultura. 3. ed. Petrópolis: Vozes, 1979.

IANNI, Octávio. Teorias da globalização. 5. ed. Rio de Janeiro: Civilização Brasileira, 1999b.

KARKOTLI, Gilson. Responsabilidade social empresarial. 2. ed. Petrópolis: Vozes, 2006.

KUNSCH, Margarida Maria Krohling. A comunicação para a sustentabilidade das organizações na sociedade global. In: KUNSCH, Margarida Maria Krohling; OLIVEIRA, Ivone de Lourdes (Org.). A comunicação na gestão da sustentabilidade das organizações. São Caetano do Sul: Difusão, 2009. p. 57-81. 
LACAN, Jacques. 0 seminário, Livro 17: o avesso da psicanálise (1969 - 1970). Rio de Janeiro: Zahar, 1992.

MÉSZÁROS, István. O século XXI. Socialismo ou barbárie. Rio de Janeiro: Boitempo Editorial, 2003.

MORIN, Edgar. Os sete saberes necessários à educação do futuro. 4. ed. São Paulo: Cortez, 2001.

PÊCHEUX, Michel. Semântica e discurso: uma crítica à afirmação do óbvio. Campinas: Unicamp, 1988.

PIKETTY, Thomas. 0 capital no século XXI. Rio de Janeiro: Intrínseca, 2013.

POSSAS, Mário. A dinâmica da economia capitalista: uma abordagem teórica. São Paulo: Brasiliense, 1987.

REVEL, Judith. Foucault: conceitos essenciais. São Paulo: Claraluz, 2002.

SAVITZ, Andrew; WEBER, Karl. A empresa sustentável: o verdadeiro sucesso é o lucro com responsabilidade social e ambiental. Rio de Janeiro: Campus, 2007.

SÓLIO, Marlene Branca. Responsabilidade social empresarial: reflexões sobre o eco desse discurso em alguns segmentos sociais. In: CONGRESSO BRASILEIRO DE CIÊNCIAS DA COMUNICAÇÃO, INTERCOM , SOCIEDADE BRASILEIRA DE ESTUDOS INTERDISCIPLINARES DA COMUNICAÇÃO, 35. , 2012, Fortaleza. Anais... São Paulo: INTERCOM, 2012.

SÓLIO, Marlene Branca. Comunicação, psicanálise e complexidade: abordagem sobre as organizações e seus sujeitos. Caxias do Sul: Educs, 2010.

SÓLIO, Marlene Branca. Responsabilidade social e sustentabilidade no contexto do século XXI. Revista Alceu, Rio de Janeiro, v. 13, n. 26, p. 176-192, jan./jun. 2013.

TYLOR, Edward Burnett. A ciência da cultura. In: CASTRO, Celso (Org.) Evolucionismo cultural: textos de Morgan, Tylor e Frazer. Rio de Janeiro: Jorge Zahar, 2005. p. 67-99.

WOLTON, Dominique. Informar não é comunicar. Porto Alegre: Sulina, 2002. 


\title{
The hard line between corporate social responsibility and globalization of the capitalist economy in the organizational communication speech.
}

\begin{abstract}
The paper speculates about the relationship between the concepts of globalization, capitalism, corporate social responsibility and organizational communication. According to theoretical discussion, it analyzes field data collected by qualitative research guided in two steps: first, a set of interviews with Neighborhood Residents Associations (Amobs) leaders, from Caxias do Sul (RS), and latter, it analyses the speech and content of promotional pieces made by one of three corporations taken from the context of respondents. With the research, we wanted to compare the corporations' speech with leaders' (representative from dwellers of their respective districts) speech, seeking to understand the kind of relationship established by them, therefore analyzing in which level it denotes an effective CSR from corporations and how citizens identify the behavior of these corporations. It seems important to reflect on this way, considering that the organization's discourse appears to be disruptive regarding their practices. Also, considering that we understand that organizations underestimate the strength of paradigmatic changes that emerge in society, as well as the ability to make cross readings (vanishing points) of the social subjects.
\end{abstract}

\section{Keywords}

Globalization. Capitalism. Corporate Social Responsibility. Organizational communication.

Recebido em 11/09/2014

Aceito em 16/03/2015 